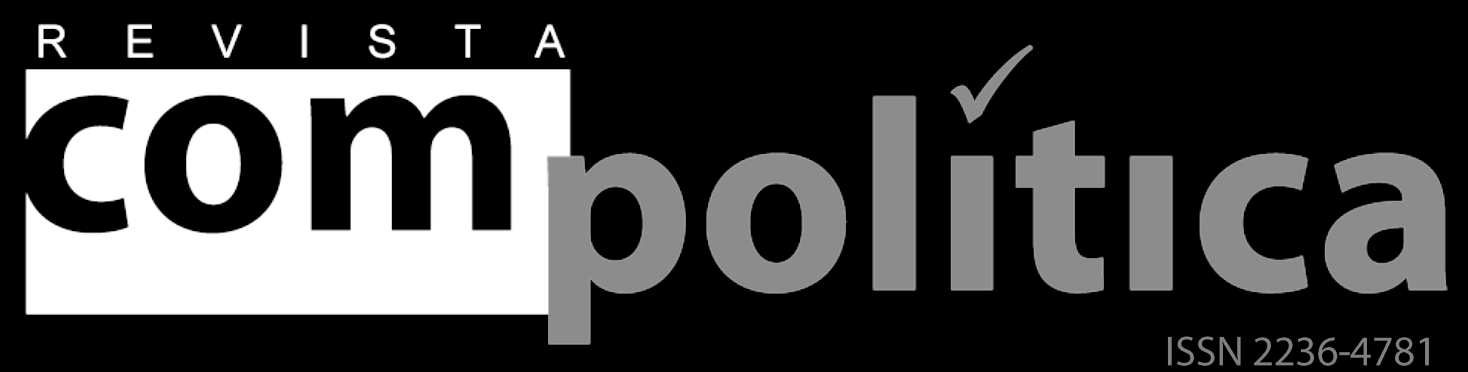

[entrevista com Wayne WANTA]

\author{
SANGLARD, Fernanda \\ Doutoranda do Programa de Pós-Graduação \\ em Comunicação da Uerj e revisora da \\ Revista Compolítica. \\ <nandanalon@yahoo.com.br>
}

As pesquisas de efeitos de mídia: uma vertente para estudar a imagem atribuída aos países pela sociedade e pelos veículos de comunicação 


\section{As pesquisas de efeitos de mídia: uma vertente para estudar a imagem atribuída aos países pela sociedade e pelos veículos de comunicação}

\section{[Research on media effects: studying the image assigned to countries by society and the media]}

SANGLARD, Fernanda [entrevista com Wayne WANTA]

$\mathrm{W}$

ayne Wanta é professor e chefe do Departamento de Jornalismo da Faculdade de Jornalismo e Comunicação da Universidade da Flórida em Gainesville, nos Estados Unidos. Considerado uma referência norte-americana nos estudos de efeitos de mídia, o pesquisador visitou o Brasil no primeiro semestre de 2014 com o propósito de conhecer o país e apresentar alguns resultados de suas pesquisas. A partir de convite da professora Sonia Virgínia Moreira, ele esteve na Universidade do Estado do Rio de Janeiro para falar aos alunos do curso de doutorado do Programa de PósGraduação em Comunicação, quando aceitou conceder esta entrevista à Compolítica.

Antes de se iniciar na vida acadêmica, Wanta atuou em redações de jornais por oito anos. Foi também presidente da Associação para a Educação em Jornalismo e Comunicação de Massa. Ele tem doutorado pela Universidade do Texas em Austin, e estudos publicados nas áreas de efeitos de mídia, comunicação política, opinião pública e jornalismo esportivo. Boa parte de seus trabalhos é dedicada a buscar compreender como o agendamento midiático pode refletir nas percepções do público.

$\mathrm{Na}$ entrevista, Wanta atribui parte da imagem positiva que o Brasil conquistou junto à população norte-americana ao estereótipo de país alegre e acolhedor, que tem um bom futebol e promove um dos maiores espetáculos do mundo, o carnaval. Segundo ele, boa parte 
das informações sobre o Brasil que chegam ao grande público são negativas ou estão atreladas a esses fatores, mas as pesquisas realizadas por ele a partir de survey demonstram que os entrevistados fazem avaliação positiva do país. O pesquisador acredita que enquanto o país continuar promovendo os espetaculares desfiles de carnaval e "ganhando Copas do Mundo", a imagem tende a permanecer assim. Será que algo vai mudar depois do campeonato deste ano? A entrevista de Wanta foi concedida antes do evento futebolístico.

Durante a passagem pela Universidade do Estado do Rio de Janeiro (Uerj) o senhor apresentou resultados de um questionário aplicado entre 1998 e 2010. Tal levantamento de dados oferecia o nome de um país e os participantes deveriam avaliar qual era a importância do citado país para os Estados Unidos. Quais foram os principais resultados dessa pesquisa, no que diz respeito às percepções e atitudes políticas?

Descobrimos que, em geral, quanto mais um país é alvo da cobertura midiática, maior é a probabilidade de o público achar que o país era de "importância vital" para os Estados Unidos. Em outras palavras, a cobertura da mídia influencia a percepção em poder do público por muitos países. A cobertura influenciou o pensamento do público sobre isso. A segunda constatação foi a de que se há mais cobertura midiática negativa sobre um país, o mais provável é que o pensamento público desse país seja pautado em termos negativos. Em outras palavras, os meios de comunicação não só influenciaram o pensamento público sobre o tema (a importância percebida de um país), mas também a forma como o pensamento público sobre os países se estabelece.

\section{Como o Brasil aparece nessas pesquisas?}

Curiosamente, o Brasil foi um dos países que não seguiram a tendência. O Brasil não recebeu cobertura de notícias positivas. No entanto, os participantes do questionário visualizaram o Brasil de forma muito positiva. Eu acho que isso é devido às ideias de longo prazo mantidas sobre o Brasil. No meu caso, quando penso em Brasil, penso em carnaval e futebol - dois atributos muito positivos. 0 futebol brasileiro é alvo do noticiário apenas a cada quatro anos, durante a Copa do Mundo, mas as impressões dos torcedores dançando e se divertindo - como acontece com o carnaval representam uma impressão mais duradoura para as pessoas. Segundo a pesquisa, esses atributos positivos permanecem em nossas 
mentes até que novos atributos substituam os antigos. Então, até que o Brasil faça algo negativo - como começar uma guerra ou apoiar o terrorismo - os atributos positivos de pessoas se divertindo permanecerão.

Onde a pesquisa foi aplicada e quantas pessoas participaram em 1998 e 2010 ? Qual foi a metodologia?

As pesquisas que usamos foram conduzidas por uma organização de pesquisa localizada em Chicago. Eles entrevistam milhares de pessoas a cada quatro anos sobre atitudes em relação a vários países. Temos usado as pesquisas para vários estudos e encontrado dados que são muito válidos e confiáveis.

Pelo que nos apresentou, nestas pesquisas também são feitas questões do tipo: "o que você diria para alguém que nunca ouviu falar de um país?" o que as pessoas disseram sobre o Brasil?

A questão tipicamente usada pelos pesquisadores é: "Se você tivesse um amigo que não conhecesse nada sobre "tal personalidade política', o que você diria a ele?" Essa pergunta tem sido extensivamente usada em estudos que lidam com a imagem de pessoas: como o presidente dos Estados Unidos. A partir dessa pergunta, os pesquisadores podem determinar dois tipos de atributos: cognitiva, ou informação factual, ou afetivas, ou em relação às valências (atitudes positivas, negativas e neutras). Nós não usamos essas perguntas sobre o Brasil. Em vez disso, foram utilizados os dados já recolhidos pela empresa de pesquisa. A questão era: "Nós vamos citar um país. Por favor, diga-nos, em uma escala de 0 a 100, sendo 0 frio e 100 quente, como você classificaria o país." A questão é voltada para os atributos afetivos - as atitudes positivas, neutras e negativas em relação aos países. O Brasil tem sido classificado como muito quente - incluído nos 30\% melhores colocados. Minha impressão é que se você perguntar a origem da questão do agendamento sobre o Brasil, você terá respostas relativas às pessoas se divertindo, ou às belas praias, ou até mesmo sobre a "Garota de Ipanema".

E esses resultados sobre o Brasil corresponderam com suas impressões quando esteve aqui?

Um importante ponto da nossa pesquisa sobre nações estrangeiras é que a maioria das pessoas nos Estados Unidos nunca viajou para o exterior. Assim, para a maioria dos americanos, a única forma de exposição a um país é através da mídia. Eu gosto de exemplificar 
referindo às minhas impressões sobre a China. Antes da minha primeira viagem à China, eu tinha pensado que todo o povo chinês seria triste por causa de seu governo. Pensava: Como alguém poderia ser feliz quando seu governo é tão dominante? Quando viajei à China, amigos me levaram a uma boate, onde as pessoas estavam rindo e dançando e se divertindo muito. As pessoas na China não estão preocupadas com o poder do seu governo. Seu governo os mantém seguros e proporciona estabilidade. Aqui está um caso em que eu substituí meu velho atributo (pessoas ficarem tristes) por um novo (as pessoas estão muito felizes). No caso do Brasil, os meus atributos originais foram: Excelente futebol, pessoas festejando e belas praias (e mulheres). Eu, certamente, não tive que substituir qualquer um dos atributos primários depois da minha viagem. Foram confirmados os meus atributos originais.

\section{A imagem do Brasil retratada nos jornais dos Estados Unidos mudou com o tempo? Se sim, em que sentido?}

Enquanto o time de futebol do Brasil continuar ganhando Copas do Mundo, e o carnaval ainda se destacar oferecendo diversão com gente bonita, acho que a imagem do Brasil vai ser muito estável. A imagem do Brasil tem sido consistente desde os dias de Carmen Miranda. Isso pode mudar no futuro, especialmente tendo em conta os problemas econômicos enfrentados nossos dois países. Recebemos apenas cobertura mínima da Cúpula Econômica em que o empurrão do nosso presidente Bush para uma zona de livre-comércio foi rejeitada. Vimos que o presidente brasileiro era um dos líderes do conflito com o presidente Bush. Mas desde que o presidente Hugo Chávez, da Venezuela, tornou-se muito mais conhecido nos EUA, ele dominou a cobertura. Eu acho que se você tivesse entrevistado pessoas nos EUA após a cúpula e pedisse suas impressões, a maioria teria as atribuído à rejeição do plano de Bush por Chávez. Mas qualquer cobertura do envolvimento do presidente brasileiro teria entrado em conflito com as nossas percepções do Brasil como lugar extremamente amigável.

\section{Como o senhor avalia a relação entre agenda pública e agendamento midiático?}

Algumas pessoas enxergam o agendamento midiático (agenda-setting) como um efeito de mídia negativo. Elas afirmam que a mídia manipula o público, controlando as questões com as quais eles estão mais preocupados. Defendo o contrário, que agenda-setting é, na verdade, um efeito positivo. Os meios de comunicação cobrem novas histórias. O público processa as histórias e aprende sobre assuntos importantes do dia. Então, agenda-setting envolve aprendizagem 
social: As pessoas aprendem sobre a sociedade. A aprendizagem é um resultado positivo.

O senhor esteve recentemente no Brasil para apresentar alguns resultados da pesquisa. Qual foi a reação dos pesquisadores brasileiros e estudantes de comunicação e jornalismo? Houve alguma surpresa?

Eu não diria que houve surpresas. Eu acho que a maioria das pessoas estava de acordo com os resultados. As pessoas veem coisas nos noticiários que elas relacionam com objetos nas notícias. No caso em que o Brasil é o "objeto", a maioria desses atributos é positiva. Quando eu discuto nossa pesquisa, eu gosto de "virar o jogo" sobre o público e perguntar: "Se você tivesse um amigo que nada saiba sobre os Estados Unidos, o que você diria a ele?" Normalmente, eu recebo respostas como "estrelas de cinema", "crime" e "McDonalds." No caso do McDonalds, o link com esse atributo é formado por experiência pessoal. O McDonalds está por todo o mundo. Mas as estrelas de cinema e crime vêm à tona a partir da mídia de massa. Como alguém no Brasil sabe que há uma porção de crimes nos Estados Unidos sem visitar os Estados Unidos e vê-lo em primeira mão? Bem, a pessoa assiste na televisão.

Sua pesquisa também está preocupada com o uso das redes sociais. Como avalia a importância de ferramentas como o Facebook e o Twitter para usuários brasileiros e de outras economias emergentes, como Índia, Indonésia, México, Rússia e China?

As mídias sociais são muito novas para realmente tirarmos quaisquer conclusões da pesquisa. Mas a mídia social provavelmente vai ter um enorme impacto no Brasil. Os dados que eu vi mostram que os brasileiros estão entre os líderes mundiais no uso de redes sociais. Isso não me surpreende, uma vez que a minha percepção dos brasileiros é que eles são extremamente simpáticos e gostam de se divertir. As mídias sociais, certamente, se prestam a essas finalidades. Mas as redes sociais prometem ter algum efeito de definição da agenda. Se eu tenho um amigo que posta mensagens no Facebook incentivando as pessoas a boicotarem a North American Van Lines (empresa transportadora do ramo de mudanças), porque eles têm um serviço terrível, eu estou sujeito a boicotar a Van Lines, porque eu confio no meu amigo.

Considera que a mídia social é, atualmente, um instrumento de participação política? 
As mídias sociais têm o potencial para ter um impacto sobre a participação política. Os amigos podem incentivar outros amigos para apoiar certas causas, ou certos candidatos políticos. Na eleição presidencial de 2008 nos Estados Unidos, Barrack Obama tinha dois milhões de amigos no Facebook. Seu adversário, John McCain, teve 600 mil. Não era algo surpreendente, portanto, que Obama tivesse uma enorme vantagem entre os eleitores mais jovens.

COMP(LITICA ASSOCIACCÃO BRASILEIRA DE PESQUISADORES EM COMUNICACÃO E POLÍTICA

Presidente: Alessandra Aldé (UERJ) Vice-Presidente: Luis Felipe Miguel (UnB) Secretário Executivo: Francisco Jamil Marques (UFC)

Editora-Chefe:

Alessandra Aldé (UERJ)

Editores Executivos:

Edna Miola (UFS) e Viktor Chagas (UFF)
A Revista Compolítica é uma revista eletrônica da Associação Brasileira de Pesquisadores em Comunicação e Política. Com periodicidade semestral, sua proposta é difundir a produção acadêmica relacionada às interfaces desses campos de estudo.

Ao citar este artigo, utilize a seguinte referência bibliográfica

SANGLARD, Fernanda. As pesquisas de efeitos de mídia: uma vertente para estudar a imagem atribuída aos países pela sociedade e pelos veículos de comunicação. In: Revista Compolítica, n. 4, vol. 1, ed. janeiro-julho, ano 2014. Rio de Janeiro: Compolítica, 2014. 
